\title{
Characteristics of Fall-Related Fractures
Adults with Cerebrovascular Disease: A Cross-Sectional Study
}

\author{
Mingming $\mathrm{Fu}^{\mathrm{l}, *}$ \\ Junfei Guo ${ }^{2, *}$ \\ Yuqi Zhao' \\ Yaqian Zhang' \\ Yingze Zhang ${ }^{2-4}$ \\ Zhiqian Wang' \\ Zhiyong $\mathrm{Hou}^{2,3}$
}

'Department of Geriatric Orthopedics, The Third Hospital of Hebei Medical University, Shijiazhuang, Hebei, People's Republic of China; ${ }^{2}$ Department of Orthopaedic Surgery, The Third Hospital of Hebei Medical University, Shijiazhuang, Hebei, 05005I, People's Republic of China; ${ }^{3} \mathrm{NHC}$ Key Laboratory of Intelligent Orthopeadic Equipment (The Third Hospital of Hebei Medical University), Shijiazhuang, Hebei, 05005I, People's Republic of China; ${ }^{4}$ Chinese Academy of Engineering, Beijing, 100088, People's Republic of China

*These authors contributed equally to this work
Correspondence: Zhiqian Wang

Department of Geriatric Orthopedics,

The Third Hospital of Hebei Medical

University, Shijiazhuang, Hebei, 05005I,

People's Republic of China

Email w18533II2890@I63.com

Zhiyong Hou

Department of Orthopaedic Surgery, The

Third Hospital of Hebei Medical

University, Shijiazhuang, Hebei, 05005I,

People's Republic of China

Email drzyhou@gmail.com
Purpose: Limited information exists on fall-related fractures in older adults with cerebrovascular disease. This study aimed to determine the characteristics of older adults with cerebrovascular disease who sustained fall-related fractures and identify the associated risk factors for perioperative complications.

Patients and Methods: This was a cross-sectional study, which included patients with cerebrovascular disease who sustained fractures between Jan. 2017 and Dec. 2019. The collected data included demographics (age and gender), time and place of fracture occurrence, mechanism of injury, fracture location, type of cerebrovascular disease, complications, and comorbidities.

Results: A total of 768 patients with 815 fractures were included; there were 253 males and 515 females, with an average age of 78.3 years. For either males or females, $80-84$ years was the most commonly involved age group. Most (61.0\%) patients had their fractures occurring at home and most fractures (70.7\%) occurred during the daytime. Most were hip fractures and limb weakness; instability-related falls were the most common cause of fracture, making a proportion of $34.5 \%$. Patients who suffered falls were mainly combining ischemic cerebrovascular disease. Most (85.9\%) patients presented with at least one comorbid disease and the perioperative complication rate was $76.9 \%$ in total cases. Age $\geq 80$ (OR: 1.772, 95\% CI: 1.236-2.540) and the number of comorbidities $\geq 3$ (OR: 1.606, 95\% CI: 1.035-2.494) were found independently associated with complications, while the type of cerebrovascular disease, fracture location, and comorbidities of prior fragility fracture and respiratory disease were not significantly correlated with complications.

Conclusion: Our findings highlighted that more focus on improved physical function explored in intervention setting and the importance of primary home prevention measures seems justified in China and maybe other countries as well. It is the first study that presented the epidemiological characteristics of older adults with cerebrovascular disease who later experienced a fracture.

Keywords: cross-sectional study, epidemiology, fall-related fracture, cerebrovascular disease, older adults

\section{Introduction}

Falls are considered a geriatric syndrome with multiple causes and contributors, which will lead to major adverse health events, including fractures, hospitalization, disability, and even death. Older people are generally at a higher risk of falls. Combined with the critical loss of bone mass, an increased propensity for falls due to deterioration of physical function can lead to the increased incidence of fractures 
in older people, especially in the hip area. ${ }^{1,2}$ There is an increased concern that about one-third of communitydwelling adults aged $\geq 65$ years in western countries fall each year and the frequency of falls and fall-related injuries increase with age. ${ }^{3}$

Cerebrovascular diseases, as one of the common diseases that endanger the health of older adults, are at high risk of imbalance or falls, which in turn significantly aggravating their condition and prognosis. These accidental events will present great pressure to the medical and healthcare centers, given the burden of fractures and the increased rates of related morbidities. Statistical data demonstrated that cerebrovascular disease is the leading cause of mortality in China, and its incidence has increased worldwide and remained high in China. ${ }^{4,5}$ Due to the higher morbidity and mortality in such a population, knowledge of characteristics in the older fractured adults combined with cerebrovascular disease is more important than ever before. However, research assessing its epidemiological behavior which is the basic prerequisite to avoid or reduce the occurrence of fractures as an important indicator of disease distribution and health status ${ }^{6}$ remains scarce.

In this study, we retrospectively collected data of hospitalized older adults with cerebrovascular disease who sustained fractures, and we aimed to investigate the characteristics in such a population. We hope these data could be useful for understanding characteristics of these specific risk populations and providing treatment recommendations for older adults in China and maybe other countries as well.

\section{Materials and Methods}

\section{Patients and Groups}

The study population consisted of all fractured patients aged 65 years or older presenting with the cerebrovascular disease at a single Level I trauma center in China between Jan. 2017 and Dec. 2019. We included patients who were 65 years or older, with a definite diagnosis of new-onset fracture by falls, had an admission delay of less than 7 days, and a principal diagnosis of cerebrovascular disease. Patients who had old fractures, pathologic fractures, secondary fractures, and patients with missing medical data were excluded. This study was approved by the institutional review board of the third Hospital of Hebei Medical University (K2020-032-1) in compliance with the Helsinki. The declaration and consent were waived for its retrospective nature and all collected patient data were anonymously recorded to protect patient confidentiality.

The collected data of interest included demographics (age and gender), time and place of fracture occurrence, mechanism of injury, fracture location, type of cerebrovascular disease (ischemic cerebrovascular disease including ischemic stroke and transient ischemic attack; cerebral hemorrhage; and asymptomatic cerebral infarction), complications and comorbidities. Based on age in the five-year interval, patients were divided into six groups: 65-69 years, 70-74 years, 75-79 years, 80-84 years, 85-89 years, and age $\geq 90$ years. The time of injury was classified as dawn (00:00-6:00), morning (6:00-12:00), afternoon (12:00-18:00), and evening (18:00-24:00). The place of fracture occurrence was recorded as indoor, outdoor, and others. The mechanism of injury was classified as limb weakness/instability during walking, sudden change in body positions, slips, trips, dizziness, stepping on an empty step, and others.

The fracture location was recorded as a proximal and distal fracture for upper/lower limb long-bone (humerus, ulna and radius, femur, tibia, and fibula), scapula, clavicle, hand fracture, foot fracture, pelvic/acetabular fracture, patella, and vertebral fracture.

Based on these definitions, information on fractures was extracted, verified, and confirmed by medical and radiological records. All electronic data were evaluated by two orthopedic surgeons not involved in patients' care, and if the consequences differed greatly, a discussion is needed.

\section{Statistical Analysis}

We performed a power analysis for statistics. A two-sided $5 \%$ significance level and $80 \%$ power were considered as reliable and significant. The sample size and the power analysis have been computed using NCSS-PASS V11.0.7 software (https://www.ncss.com/software/pass/). The categorical data were expressed as absolute numbers and percentage (\%) and were evaluated by chi-square or Fisher's exact test. Multivariate logistic regression was performed to assess the contributions of variables that demonstrated to be independently related to adverse outcomes as candidate predictor variables with perioperative complications. In the multi-category variables, ischemic stroke and trunk fracture were chosen as standard, others were converted into dummy variables. We adjusted for the covariates with a $p$-value $<0.10$ in the final multivariate logistic models. All data analyses were performed using IBM SPSS 
Statistics for Windows, version 26.0 (IBM, Armonk, NY, USA). The forest plots illustrating the results of multivariate Logistic regression were performed in $\mathrm{R}$ version 3.5.1. The level of significance was set at $P<0.05$.

\section{Results}

\section{Place and Time of Fracture Occurrence, and Injury Mechanism}

A total of 468 patients had their fractures occurring at their own home, taking a proportion of $61.0 \% ; 281$ (36.6\%) patients had their fractures occurring at the community court or on the way to or from outside; 19 patients had their fractures occurring at other places included public sites (market, park, hospital, etc.), staircase, and sports field. Among 768 patients, most fractures (543 patients, $70.7 \%$ ) occurred during the daytime, especially in the afternoons (333 patients, $43.4 \%$ ). The proportion of limb weakness or instability-related falls causing fractures was $34.5 \%$ (265/768), followed by fall from a sudden change in body positions $(203,26.4 \%)$, slipping $(148,19.3 \%)$, tripping (58, $7.6 \%)$, others $(57,7.4 \%)$, dizziness $(19,2.5 \%)$, and stepping on an empty step $(18,2.4 \%)$ (Table 1$)$.

\section{Fracture Location}

Among 815 fractures, there were 596 hip fractures (including 242 femoral neck fractures and 354 intertrochanteric fractures), accounting for $73.1 \%$ (29.7\% and $43.4 \%$ for femoral neck fracture and intertrochanteric fracture, respectively), followed by proximal humerus fracture (48, 5.9\%), and vertebral fracture (32, 3.9\%) (see Table 2).

Of the $45(5.9 \%)$ patients with concurrent fractures (92 fractures, total), $30(3.9 \%)$ patients fell due to weakness/ instability and slips, while 15 patients fell from a sudden change in body positions. Thirty-two patients with at least one lower-extremity diaphyseal fracture involved in each, with concurrent vertebral fracture, acetabulum fracture, or foot fracture. Ten patients with at least one upperextremity diaphyseal fracture involved in each, with concurrent vertebral fracture or acetabulum fracture. There were other 2 patients who presented with vertebral fracture and acetabulum fracture.

\section{Age- and Gender-Specific Characteristics}

From Jan. 2017 to Dec. 2019, a total of 822 fractured patients presenting with the cerebrovascular disease were screened and assessed for eligibility to participate in this study. The number of falls-related fractures in this cohort
Table I The Distribution of Place and Time of Fracture Occurrence, and Injury Mechanism

\begin{tabular}{|c|c|c|}
\hline Variables & Cases & Percentage (\%) \\
\hline \multicolumn{3}{|l|}{ Place } \\
\hline \multicolumn{3}{|l|}{ Indoor } \\
\hline Living room & 194 & 25.3 \\
\hline Bathroom & 145 & 18.9 \\
\hline Bedroom & $|2|$ & 15.8 \\
\hline Kitchen & 8 & 1.0 \\
\hline $\begin{array}{l}\text { Outdoor (community court or on } \\
\text { the way to or from outside) }\end{array}$ & 281 & 36.6 \\
\hline $\begin{array}{l}\text { Other places (public sites including } \\
\text { market, park, hospital; staircase; and } \\
\text { sports field) }\end{array}$ & 19 & 2.5 \\
\hline \multicolumn{3}{|l|}{ Time } \\
\hline Dawn (00:00-6:00) & 55 & 7.2 \\
\hline Morning (6:00-12:00) & 210 & 27.3 \\
\hline Afternoon (12:00-18:00) & 333 & 43.4 \\
\hline Evening (I8:00-24:00) & 170 & 22.1 \\
\hline \multicolumn{3}{|l|}{ Injury mechanism } \\
\hline Instability or weakness & 265 & 34.5 \\
\hline Sudden change in body positions & 203 & 26.4 \\
\hline Slips & 148 & 19.3 \\
\hline Trips & 58 & 7.6 \\
\hline Dizziness & 19 & 2.5 \\
\hline Stepping on an empty step & 18 & 2.4 \\
\hline Others & 57 & 7.4 \\
\hline
\end{tabular}

was 768 and all of them met our inclusion and exclusion criteria. Among 768 patients, 210 (27.34\%) occurred in 2017, 258 (33.59\%) in 2018, and 300 (39.07\%) in 2019. During the study period, there were a total of 768 patients with 815 fractures, including 43 patients each having concurrent two fractures and two patients each with concurrent three fractures.

There were 253 (32.94\%) male patients and 515 (67.06\%) female patients, with an average age of 78.3 years (standard deviation, SD, 7.7 years; range, 65 to 110). The mean (SD) age at fracture was 77.9 years (7.8) for males and 78.6 years (7.7) for females with a range of 65-110 and 65-106 for males and females, respectively. Although not statistically significant $(P>0.05)$, the ratios were higher among females than males within all age groups $(1.75,1.82,2.45,1.90,2.26$, and 2.33 in each age group). For either males or females, $80-84$ years was the most commonly involved age group. The detailed 
Table 2 The Distribution of Fracture Based on Different Locations

\begin{tabular}{|c|c|c|}
\hline Fracture Location & Cases & Percentage (\%) \\
\hline \multicolumn{3}{|l|}{ Humeral fracture } \\
\hline Proximal & 48 & 5.9 \\
\hline Shaft & 3 & 0.4 \\
\hline Distal & 11 & 1.3 \\
\hline \multicolumn{3}{|l|}{ Ulna and radius fracture } \\
\hline Proximal & 6 & 1.2 \\
\hline Shaft & 4 & 0.5 \\
\hline Distal & 11 & 1.3 \\
\hline \multicolumn{3}{|l|}{ Femoral fracture } \\
\hline \multicolumn{3}{|l|}{ Proximal } \\
\hline Femur neck fracture & 242 & 29.7 \\
\hline Femur intertrochanteric fracture & 354 & 43.4 \\
\hline Shaft & 13 & 1.6 \\
\hline Distal & 17 & 2.1 \\
\hline \multicolumn{3}{|l|}{ Tibia and fibula } \\
\hline Proximal & 6 & 0.7 \\
\hline Shaft & 2 & 0.2 \\
\hline Distal & 12 & 1.5 \\
\hline Scapular fracture & 3 & 0.4 \\
\hline Clavicle fracture & 9 & 1.1 \\
\hline Hand fracture & 1 & 0.1 \\
\hline Foot fracture & 4 & 0.5 \\
\hline Pelvic/ acetabular fracture & 19 & 2.3 \\
\hline Patella fracture & 18 & 2.2 \\
\hline Vertebra fracture & 32 & 3.9 \\
\hline
\end{tabular}

characteristics stratified by age and gender are presented in Table 3 and Figure 1. No clear seasonal variation in fractures was observed (data not shown).

\section{Type of Cerebrovascular Disease}

Table 3 shows the fractured patients who suffered falls were mainly combining ischemic cerebrovascular disease including ischemic stroke $(541,70.4 \%)$ and transient ischemic attack $(23,3.0 \%)$. There were $55(7.2 \%)$ cases of cerebral hemorrhage and 149 (19.4\%) cases of asymptomatic cerebral infarction, respectively. In addition, ischemic stroke was performed in 15 of the 55 cases of a cerebral hemorrhage. Further analysis showed that females had higher ratios than males $(50.0 \%$ vs $23.5 \%$ and $13.3 \%$ vs $6.1 \%)$ in ischemic cerebrovascular disease and asymptomatic cerebral infarction. However, gender did not differ between hemorrhagic cerebrovascular disease and ischemic stroke combining with cerebral hemorrhage groups $(P>0.05)$.

\section{Comorbidities and Complications}

Among all patients, 660 patients were presenting with at least one comorbid disease, accounting for $85.9 \%$, which consisted predominantly of hypertension $(62.9 \%)$, coronary heart disease $(33.6 \%)$, and diabetes $(30.5 \%)$. The perioperative complication rate was $76.9 \%$ in total cases including anemia $(\mathrm{n}=304,39.6 \%)$, hypoproteinemia $(\mathrm{n}=304,39.6 \%)$, deep vein thrombosis $(\mathrm{n}=289,37.6 \%)$, electrolyte disorders $(\mathrm{n}=265,34.5 \%)$, perioperative hyperglycemia $(\mathrm{n}=226,29.4 \%)$, cardiac complications $(\mathrm{n}=215,28.0 \%)$, and pulmonary complications (74, 9.6\%). Further analysis showed that females had higher ratios than males in all subgroups of comorbidities and complications aforementioned $(P<0.05)$, except for arrhythmia, respiratory disease, rheumatic immune disease, Parkinson's disease, neuropsychiatric disorders, and pulmonary complications $(P>0.05)$. The distribution of comorbidities and complications in males and females are shown in Table 3.

\section{Analysis of Possible Influencing Factors of Perioperative Complications}

To examine the association between perioperative complications and all factors that could causatively be related to, we performed multivariate logistic regression on total patients. As shown in Table 4, unadjusted analyses showed that factors associated with the perioperative complications were age, type of cerebrovascular disease, fracture location, comorbidities of prior fragility fracture and respiratory disease, and the number of comorbidities $(P<0.01)$. After adjusting for the covariates with $p$-value $<0.1$ in the univariate analyses, the adjusted odds ratio (OR) provided the association with perioperative complications and covariates in the multivariate logistic model. Covariates of age $\geq 80$ (OR: 1.772, 95\% CI: 1.236-2.540) and the number of comorbidities $\geq 3$ (OR: $1.606,95 \% \mathrm{CI}$ : 1.035-2.494) were found independently associated with complications. It appeared that type of cerebrovascular disease, fracture location, and comorbidities of prior fragility fracture and respiratory disease were not significantly correlated with complications (Figure 2). 
Table 3 The Detailed Distribution of Age, Age Group, Type of Cerebrovascular Disease, Comorbidities and Complications Stratified by Gender

\begin{tabular}{|c|c|c|c|c|}
\hline Variables & Total & Male & Female & $P$ value \\
\hline Number of patients, $n$ (\%) & $768(100)$ & $253(32.9)$ & $515(61.7)$ & \\
\hline Age, years & $78.3 \pm 7.7$ & $77.9 \pm 7.8$ & $78.6 \pm 7.7$ & 0.276 \\
\hline Age, years (range) & $65-110$ & $65-110$ & $65-106$ & \\
\hline $\begin{array}{l}\text { Age groups, n (\%) } \\
\text { 65-69 } \\
70-74 \\
75-79 \\
80-84 \\
85-89 \\
\geq 90\end{array}$ & $\begin{array}{c}|2|(I 5.8) \\
\text { I4I (I8.4) } \\
\text { I52(I9.8) } \\
\text { I80 (23.4) } \\
\text { I24 (I6.I) } \\
50(6.5)\end{array}$ & $\begin{array}{l}44(36.4) \\
50(35.5) \\
44(28.9) \\
62(34.4) \\
38(30.6) \\
15(30.0)\end{array}$ & $\begin{array}{c}77(63.6) \\
91(64.5) \\
108(7 I .1) \\
118(65.6) \\
86(69.4) \\
35(70.0)\end{array}$ & 0.728 \\
\hline \multicolumn{5}{|l|}{ Type of cerebrovascular disease, $n(\%)$} \\
\hline $\begin{array}{l}\text { Ischemic stroke } \\
\text { Transient ischemic attack }\end{array}$ & $\begin{array}{c}541(70.4) \\
23(3.0)\end{array}$ & $\begin{array}{l}174(22.7) \\
6(0.8)\end{array}$ & $\begin{array}{c}367(47.8) \\
17(2.2)\end{array}$ & $\begin{array}{l}<0.00 I^{*} \\
0.022^{*}\end{array}$ \\
\hline \multicolumn{5}{|l|}{ Hemorrhagic cerebrovascular disease } \\
\hline Cerebral hemorrhage & $55(7.2)$ & $26(3.4)$ & $29(3.8)$ & 0.686 \\
\hline $\begin{array}{l}\text { Cerebrovascular disease without acute focal neurologi } \\
\text { Asymptomatic cerebral infarction }\end{array}$ & 149 (19.4) & $47(6.1)$ & $102(13.3)$ & $<0.001 *$ \\
\hline Ischemic stroke combining with cerebral hemorrhage & $15(2.0)$ & $8(1.0)$ & $7(0.9)$ & 0.796 \\
\hline \multicolumn{5}{|l|}{ Comorbidities, n (\%) } \\
\hline Hypertension & $483(62.9)$ & $143(18.6)$ & $340(44.3)$ & $<0.001 *$ \\
\hline Coronary heart disease & $258(33.6)$ & $78(10.2)$ & $180(23.4)$ & $<0.001 *$ \\
\hline Diabetes & $234(30.5)$ & $69(9.0)$ & $165(2 \mid .5)$ & $<0.001 *$ \\
\hline Prior fragility fracture & $119(15.5)$ & $35(4.6)$ & $84(10.9)$ & $<0.001 *$ \\
\hline Arrhythmia & $46(6.0)$ & $23(3.0)$ & $23(3.0)$ & 1.000 \\
\hline Respiratory disease & $51(6.6)$ & $27(3.5)$ & $24(3.1)$ & 0.674 \\
\hline Knee osteoarthritis & $44(5.7)$ & $14(1.8)$ & $30(3.9)$ & $0.016 *$ \\
\hline Malignant neoplasm & $27(3.5)$ & $8(1.0)$ & $19(2.5)$ & $0.034 *$ \\
\hline Chronic kidney disease & $18(2.3)$ & $4(0.5)$ & $14(1.8)$ & $0.018^{*}$ \\
\hline Rheumatic immune disease & II (I.4) & $3(0.4)$ & $8(1.0)$ & 0.132 \\
\hline Parkinson's disease & $9(1.2)$ & $3(0.4)$ & $6(0.8)$ & 0.317 \\
\hline Neuropsychiatric disorders & $6(0.8)$ & $\mathrm{I}(0.1)$ & $5(0.7)$ & 0.102 \\
\hline \multicolumn{5}{|l|}{ Perioperative complications, n (\%) } \\
\hline Anemia & $304(39.6)$ & $89(11.6)$ & $215(28.0)$ & $0.014 *$ \\
\hline Hypoproteinemia & $304(39.6)$ & $88(11.5)$ & $216(28.1)$ & $<0.00 I^{*}$ \\
\hline Deep vein thrombosis & $289(37.6)$ & $89(11.6)$ & $200(26.0)$ & $<0.001 *$ \\
\hline Electrolyte disorders & $265(34.5)$ & $83(10.8)$ & $182(23.7)$ & $<0.00 I^{*}$ \\
\hline Perioperative hyperglycemia & $226(29.4)$ & $78(10.2)$ & $148(19.3)$ & $<0.00 I^{*}$ \\
\hline Cardiac complications & $215(28.0)$ & $61(7.9)$ & $154(20.1)$ & $<0.001 *$ \\
\hline Pulmonary complications & $74(9.6)$ & $34(4.4)$ & $40(5.2)$ & 0.485 \\
\hline
\end{tabular}

Notes: Plus-minus values are means \pm SD. In number of patients, age groups, type of cerebrovascular disease, comorbidities, and perioperative complications, values are presented as the number $(\%)$. $* P<0.05$, statistical significance.

\section{Discussion}

In this cohort of 768 older adults, we examined baseline characteristics of participants who experienced a fallrelated fracture. Participants who experienced fractures were mostly occurring at home $(61.0 \%)$ and during the daytime (70.7\%). Most patients suffered from hip fractures and limb weakness or instability-related falls were the most common cause of fracture, making a proportion of 


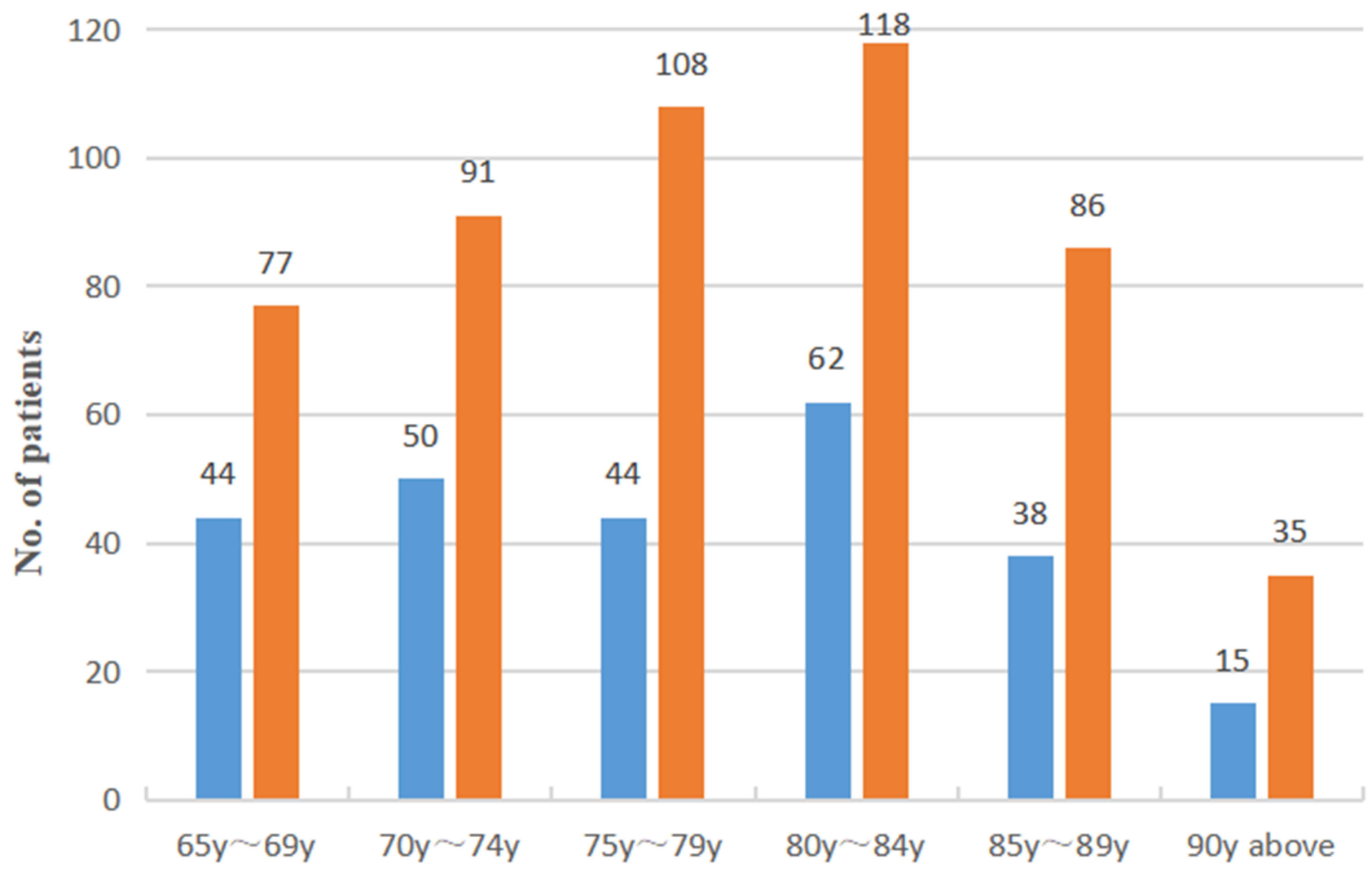

Distribution of different age group

\section{Male $\square$ Female}

Figure I The detailed distribution of fracture stratified by age and gender.

$34.5 \%$. Most (85.9\%) patients presented with at least one comorbid disease and the perioperative complication rate was $76.9 \%$ in total cases. After adjusting for covariates, age $\geq 80$ and the number of comorbidities $\geq 3$ were identified as risk factors for perioperative complications.

Cerebrovascular disease refers to a group of diseases where impaired intracranial blood circulation and vasculature blood circulation disorder are presented, which in turn leads to the damage of the central nervous system. Older adults represented the majority of such patients and can be largely divided into two categories: hemorrhagic and ischemic, which are characterized by high morbidity, high disability, high mortality, high recurrence rates, and seriously endangers human life. ${ }^{7}$ As a developing country and a rapidly aging society, China has increasing populations of both older adults and individuals who suffered from cerebrovascular disease. In addition, as a major health problem for these older adults in terms of reduced quality of life and life expectancy, fall-related fractures gained increased concern among the older adults due to the more prevalent osteopenia and osteoporosis with aging. ${ }^{2,8,9}$ As reported, approximately $60 \%$ of residents fall at least once per year, and $30 \%$ of falls cause injury. ${ }^{10}$ According to a survey from the United States, ${ }^{11}$ an estimated 33,000 fall-related deaths were reported among older community-dwelling adults, which means falls are the leading cause of injury-related morbidity and mortality among older adults.

Our study shows that falls are the main cause of fractures in older adults with cerebrovascular diseases and the number of older adults with fractures and cerebrovascular diseases is also increasing year by year, which is consistent with previous studies. ${ }^{3-5}$ The reasonable interpretation of that is the older adults with cerebrovascular diseases have a higher proportion of inability to maintain balance (ie, postural instability) and are more likely to falls, ${ }^{12}$ yet 
Table 4 The Association of Complications with Gender, Age, Type of Cerebrovascular Disease, Fracture Location, Comorbidities, and Number of Comorbidities

\begin{tabular}{|c|c|c|c|c|}
\hline \multirow[t]{2}{*}{ Variables } & \multirow[t]{2}{*}{ Total } & \multicolumn{2}{|c|}{ Complications } & \multirow[t]{2}{*}{$P$ value } \\
\hline & & Yes & No & \\
\hline Gender & & & & 0.501 \\
\hline Male & 253 & $191(75.5)$ & $62(24.5)$ & \\
\hline Female & 515 & $400(77.7)$ & $115(22.3)$ & \\
\hline Age & & & & $<0.001 *$ \\
\hline$<80$ & 414 & $298(72.0)$ & $116(28.0)$ & \\
\hline$\geq 80$ & 354 & $293(82.8)$ & $61(17.2)$ & \\
\hline Type of cerebrovascular disease & & & & $0.077^{*}$ \\
\hline Ischemic stroke & 541 & $409(75.6)$ & $132(24.4)$ & \\
\hline Transient ischemic attack & 23 & $17(73.9)$ & $6(26.1)$ & \\
\hline Asymptomatic cerebral infarction & 149 & $127(85.2)$ & $22(14.8)$ & \\
\hline Cerebral hemorrhage & 40 & $28(70.0)$ & $12(30.0)$ & \\
\hline $\begin{array}{l}\text { Ischemic stroke combining with } \\
\text { cerebral hemorrhage }\end{array}$ & 15 & $10(66.7)$ & $5(33.3)$ & \\
\hline Fracture location & & & & $<0.001 *$ \\
\hline Upper limb fracture & 59 & $33(55.9)$ & $26(44.1)$ & \\
\hline Lower limb fracture & 633 & $505(79.8)$ & $128(20.2)$ & \\
\hline Trunk fracture & 31 & $20(64.5)$ & II (35.5) & \\
\hline Multiple fracture & 45 & $33(73.3)$ & $12(26.7)$ & \\
\hline \multicolumn{5}{|l|}{ Comorbidities } \\
\hline Hypertension & 483 & $373(77.2)$ & $110(22.8)$ & 0.815 \\
\hline Coronary heart disease & 258 & $205(79.5)$ & $53(20.5 \%)$ & $0.24 I$ \\
\hline Diabetes & 234 & I 74 (74.4) & $60(25.6)$ & 0.258 \\
\hline Prior fragility fracture & 122 & $102(83.6)$ & $20(16.4)$ & $0.057^{*}$ \\
\hline Arrhythmia & 56 & $45(80.4)$ & II (19.6) & 0.530 \\
\hline Respiratory disease & 51 & $45(88.2)$ & $6(11.8)$ & $0.048^{*}$ \\
\hline Knee osteoarthritis & 44 & $37(77.3)$ & $7(22.7)$ & 0.247 \\
\hline Number of comorbidities & & & & $0.042 *$ \\
\hline$<3$ & 590 & $444(75.3)$ & $146(24.7)$ & \\
\hline$\geq 3$ & 178 & I 47 (82.6) & $31(17.4)$ & \\
\hline
\end{tabular}

Notes: Values are presented as the number $(\%) . * P<0.1$, statistical significance.

rapid bone loss after a stroke induces serious bone loss and osteoporosis, and prone to have a fracture after a fall. This suggests that more weight needs to be given to developing fall prevention interventions, also note appropriate activities in post-stroke rehabilitation and the importance of calcium and vitamin D supplements, then slow the progression of osteoporosis after stroke. A recent study has reported that pharmacological treatment of osteoporosis is necessary to reduce the risk of fractures in older patients during the rehabilitation phase of stroke recovery. ${ }^{13}$

There were more female patients included in the study, which is due to females tend to live longer but are in poorer health than males late-in-life. ${ }^{14,15}$ In general, this is probably because the prevalence of osteoporosis is much higher in women than in men and suffers the majority of osteoporotic bone fractures. $^{16,17}$ In this study, we also found most patients had their fractures occurring at home, taking approximately three-fifths of the overall fractures. And fractures (543 patients, 70.7\%) occurred mostly during daytime (especially in the afternoon), with the main causes of fall-related fractures included limb weakness or instability, sudden change in body positions, slips, and trips, etc. Our findings of no clear seasonal variation in fractures were remarkably different from the previous study by Zheng et al. ${ }^{18}$ The detailed reasons for this include our subject was older adults with 


\section{Covariates}

$$
\text { Age }(>=80)
$$

Type of cerebrovascular disease

TIA

$\mathrm{ACl}$

$\mathrm{CH}$

ISCCH

\section{Fracture location}

ULF

LLF

MF

\section{Comorbidities}

PFF

$\mathrm{RD}$

\section{Number of comorbidities $(>=3)$}

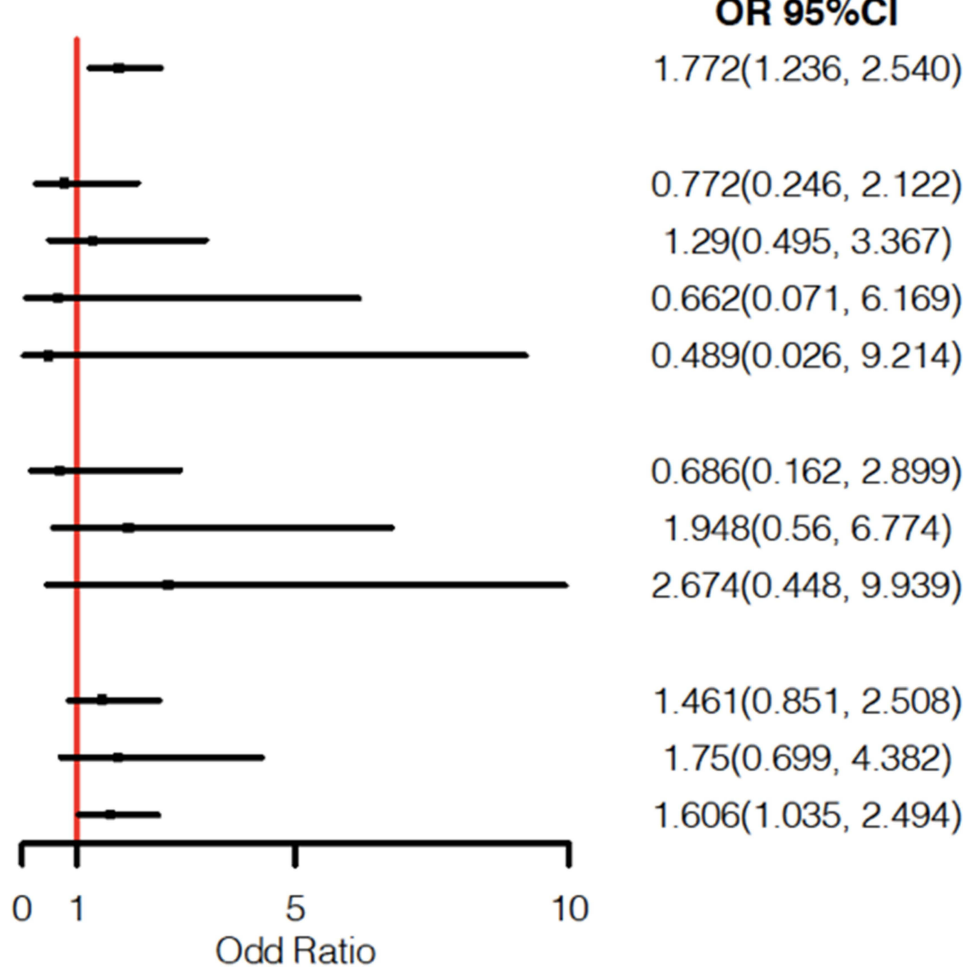

Figure 2 Multivariate logistic regression analysis result of covariates odds ratios (OR) for complications. The adjusted OR provides the association of covariates and complications after adjusting for variables with a p-value $<0.1$ in the unadjusted model. Squares represent ORs and lines represent $95 \%$ confidence intervals. The ORs are on logarithmic scale.

Abbreviations: TIA, Transient ischemic attack; ACI, Asymptomatic cerebral infarction; $\mathrm{CH}$, Cerebral hemorrhage; ISCCH, Ischemic stroke combining with cerebral hemorrhage; ULF, Upper limb fracture; LLF, Lower limb fracture; MF, Multiple fracture; PFF, Prior fragility fracture; RD, Respiratory disease.

cerebrovascular disease who were more limited in their activity at home. Our data also showed that the disproportionately high prevalence (more than seventy percent) of hip fractures was a concern, which is consistent with previous studies that the risk of subsequent hip fracture after a fall of older adults is increasing, leading to a significant risk of morbidity and mortality. ${ }^{19,20}$ Moreover, numerous studies proved that the risk of hip fracture is increasing among stroke patients. ${ }^{21,22}$ It can be predicted that this will present a heavy socioeconomic pressure on medical and society, given the burden of hip fracture and the increased rate of related morbidities.

Patients with cerebrovascular abnormalities often live with psychological and psychological disorders, which would firstly result in the decrease in the range of activities and tend to spend most of the time at home, and secondly increase the opportunity to fall. In addition, anterior circulation vascular disease is likely to cause hemiplegia while posterior circulation vascular disease is more prone to cause ataxia, indicating that elderly comorbidities can predispose them to trauma. Also, psychological factors may contribute to the fear of falling in community-dwelling older people, then the older adults tend to artificially exercise less or excessive inappropriate sporting behavior. Thus, a vicious circle is formed. ${ }^{23}$ Previous studies have shown that environmental assessments, appropriate use of walking aids, possibly home alterations, and the involvement of the caregiver should be considered to reduce fall frequency. ${ }^{24,25}$

In the current study, ischemic cerebrovascular disease is the predominant form of cerebrovascular disease. This is consistent with findings of previous studies. ${ }^{4,26}$ Adequate evidence have demonstrated the higher morbidity and mortality rate in older adults with cerebrovascular disease. ${ }^{27-29}$ Furthermore, the physical deterioration, prevalent comorbidities, and the potential psychological effects generally lead to a worse outcome in such population after a fracture. After multivariate logistic regression on total patients involved in this study, our data demonstrated that age $\geq 80$ and the number of comorbidities $\geq 3$ are independently associated with perioperative complications in fall-related fractured patients with the cerebrovascular disease while the type of cerebrovascular disease, fracture location, and comorbidities of prior fragility fracture and respiratory disease were not 
significantly correlated with complications. It is worth noting and we need to interpret the results with caution that there seems to be no correlation between gender and the occurrence of perioperative complications in multivariate logistic regression, which has been reported in previous articles. ${ }^{30-32}$ However, the current study showed that females have higher ratios than males in some types of cerebrovascular disease, comorbidities, and some specific kinds of complications, such as anemia, hypoproteinemia, deep vein thrombosis, electrolyte disorders, perioperative hyperglycemia, and cardiac complications. Our data of comorbidities and complications suggest that reasonable decision-making for perioperative management of fractures in older adults with the cerebrovascular disease will be of great significance. At present, falls in older adults are a complex public health issue that requires a multifaceted approach to identify the risk factors and develop effective interventions to target these populations. Since a large portion of falls can be prevented, and due to the high costs of hip fractures, we believe that a change in Chinese healthcare policy is required. Accordingly, how to mitigate psychological concern, is also a topic that needs to be paid attention to.

\section{Limitations}

Some potential limitations should be considered. Firstly, the inherent limitation of retrospective design and the clinical information collected from only one hospital, so the conclusions obtained cannot fully and reliably demonstrate the overall clinical features and prognosis. Secondly, some indexes such as length of stay and impact on admission cost and indexes directly related to osteoporosis fractures, such as bone density and bone mass, are not included. In addition, dietary vitamin $\mathrm{D}$ and calcium intakes and the use of vitamin D supplements or medications that can affect vitamin D metabolism were not recorded.

\section{Conclusions}

Age $\geq 80$ and the number of comorbidities $\geq 3$ are independently associated with perioperative complications in these fall-related fractured patients with cerebrovascular disease. Preventive strategies are exceptionally important for these older adults, and our data demonstrate more focus on improved physical function explored in intervention setting and the importance of primary home prevention measures seem justified in China and maybe other countries as well. This is the first study that presented the epidemiological characteristics of older adults with cerebrovascular disease who later experienced a fracture.

\section{Data Sharing Statement}

The data used to support the findings of this study are available from Zhiqian Wang upon request.

\section{Ethical Approval and Informed Consent}

This study was approved by the institutional review board of the third Hospital of Hebei Medical University (K2020032-1) in compliance with the Helsinki and the declaration and consent were waived for its retrospective nature. We declare that all collected patient data were anonymously recorded to protect patient confidentiality.

\section{Funding}

The study was financially supported by the 2019 Hebei Provincial Department of Finance Geriatric Disease Prevention and Control Funds.

\section{Disclosure}

The authors declare that there is no conflict of interest regarding the publication of this paper.

\section{References}

1. Skuladottir SS, Ramel A, Hjaltadottir I, et al. Characteristics of incidence hip fracture cases in older adults participating in the longitudinal AGES-Reykjavik study. Osteoporosis Int. 2020.

2. Westbury LD, Syddall HE, Fuggle NR, et al. Long-term rates of change in musculoskeletal aging and body composition: findings from the health, aging and body composition study. Calcif Tissue Int. 2020;106(6):616-624.

3. Conzade R, Phu S, Vogrin S, et al. Changes in nutritional status and musculoskeletal health in a geriatric post-fall care plan setting. Nutrients. 2019;11:7.

4. Zhang X, Cao X, Xu X, Li A, Xu Y. Correlation between the $-1562 \mathrm{C} /$ $\mathrm{T}$ polymorphism in the matrix metalloproteinase- 9 gene and hemorrhagic transformation of ischemic stroke. Exp Ther Med. 2015;9 (3):1043-1047.

5. Wang J, Zhang Y, Xu F. Function and mechanism of microRNA-210 in acute cerebral infarction. Exp Ther Med. 2018;15(2):1263-1268.

6. Chen W, Lv H, Liu S, et al. National incidence of traumatic fractures in China: a retrospective survey of 512187 individuals. Lancet Global Health. 2017;5(8):e807-e817.

7. Wang W, Jiang B, Sun H, et al. Prevalence, incidence, and mortality of stroke in China: results from a nationwide population-based survey of 480687 adults. Circulation. 2017;135(8):759-771.

8. Kim J, Cho KH, Lee SG, Lee YS, Jang SI, Park EC. Differences in fracture incidence according to caregiver type in stroke survivors. J Stroke Cerebrovasc Dis. 2018;27(10):2849-2856.

9. Zhang Q, Cai W, Wang G, Shen X. Prevalence and contributing factors of osteoporosis in the elderly over 70 years old: an epidemiological study of several community health centers in Shanghai. Ann Palliat Med. 2020;9(2):231-238. 
10. Mackey DC, Lachance CC, Wang PT, et al. The Flooring for Injury Prevention (FLIP) Study of compliant flooring for the prevention of fall-related injuries in long-term care: a randomized trial. PLoS Med. 2019;16(6):e1002843.

11. Guirguis-Blake JM, Michael YL, Perdue LA, Coppola EL, Beil TL. Interventions to prevent falls in older adults: updated evidence report and systematic review for the US Preventive Services Task Force. JAMA. 2018;319(16):1705-1716.

12. Mansfield A, Inness EL, McIlroy WE. Stroke. Handb Clin Neurol. 2018;159:205-228.

13. Pavone V, Testa G, Giardina SMC, Vescio A, Restivo DA, Sessa G. Pharmacological therapy of osteoporosis: a systematic current review of literature. Front Pharmacol. 2017;8:803.

14. Archer CR, Recker M, Duffy E, Hosken DJ. Intralocus sexual conflict can resolve the male-female health-survival paradox. Nat Commun. 2018;9(1):5048.

15. Nomura Y, Shimada M, Kakuta E, et al. Mortality-and health-related factors in a community-dwelling of oldest-older adults at the age of 90: a 10-year follow-up study. Int J Environ Res Public Health. 2020;17:24.

16. Hannemann A, Friedrich N, Spielhagen C, et al. Reference intervals for serum osteocalcin concentrations in adult men and women from the study of health in Pomerania. BMC Endocr Disord. 2013;13:11.

17. Cawthon PM. Gender differences in osteoporosis and fractures. Clin Orthop Relat Res. 2011;469(7):1900-1905.

18. Zheng Y, Wang X, Zhang ZK, et al. Bushen Yijing Fang reduces fall risk in late postmenopausal women with osteopenia: a randomized double-blind and placebo-controlled trial. Sci Rep. 2019;9(1):2089.

19. Aicale R, Tarantino D, Maffulli N. Prevalence of hyponatremia in elderly patients with hip fractures: a two-year study. Med Principles Pract. 2017;26(5):451-455.

20. Vu T, Day L, Finch CF. Linked versus unlinked hospital discharge data on hip fractures for estimating incidence and comorbidity profiles. BMC Med Res Methodol. 2012;12:113.

21. Wu CH, Liou TH, Hsiao PL, Lin YC, Chang KH. Contribution of ischemic stroke to hip fracture risk and the influence of gender difference. Arch Phys Med Rehabil. 2011;92(12):1987-1991.

22. Luan L, Li R, Wang Z, et al. Stroke increases the risk of hip fracture: a systematic review and meta-analysis. Osteoporosis Int. 2016;27 (11):3149-3154.
23. Walsh M, Galvin R, Horgan NF. Fall-related experiences of stroke survivors: a meta-ethnography. Disabil Rehabil. 2017;39(7):631-640.

24. Madanat R, Mäkinen TJ, Ovaska MT, Soiva M, Vahlberg T, Haapala J. Dislocation of hip hemiarthroplasty following posterolateral surgical approach: a nested case-control study. Int Orthop. 2012;36(5):935-940.

25. Cattaneo D, Gervasoni E, Pupillo E, et al. Educational and exercise intervention to prevent falls and improve participation in subjects with neurological conditions: the NEUROFALL randomized controlled trial. Front Neurol. 2019;10:865.

26. Zou JB, Chai HB, Zhang XF, et al. Reconstruction of the IncRNA-miRNA-mRNA network based on competitive endogenous RNA reveal functional lncRNAs in Cerebral Infarction. Sci Rep. 2019;9(1):12176.

27. Qiu J, Wang X, Wu F, et al. Low dose of apelin-36 attenuates ER stress-associated apoptosis in rats with ischemic stroke. Front Neurol. 2017;8:556.

28. Zhao X, Yu L, Chen Y, Wang Y, Wan H, Yang J. Comparative Pharmacokinetics of Hydrophilic Components in Salvia miltiorrhiza Bge. and Carthamus tinctorius L. in rats that underwent cerebral ischemia reperfusion using an HPLC-DAD Method. Front Pharmacol. 2019;10:1598.

29. Georgescu MM, Pinho Mda C, Richardson TE, et al. The defining pathology of the new clinical and histopathologic entity ACTA2-related cerebrovascular disease. Acta Neuropathologica Commun. 2015;3:81.

30. Smith T, Pelpola K, Ball M, Ong A, Myint P. Pre-operative indicators for mortality following hip fracture surgery: a systematic review and meta-analysis. Age Ageing. 2014;43(4):464-471.

31. Brauer C, Coca-Perraillon M, Cutler D, Rosen A. Incidence and mortality of hip fractures in the United States. JAMA. 2009;302 (14):1573-1579.

32. Roth T, Kammerlander C, Gosch M, Luger T, Blauth M. Outcome in geriatric fracture patients and how it can be improved. Osteoporosis Int. 2010;21:S615-619.
Clinical Interventions in Aging

\section{Publish your work in this journal}

Clinical Interventions in Aging is an international, peer-reviewed journal focusing on evidence-based reports on the value or lack thereof of treatments intended to prevent or delay the onset of maladaptive correlates of aging in human beings. This journal is indexed on PubMed Central, MedLine, CAS, Scopus and the Elsevier

\section{Dovepress}

Bibliographic databases. The manuscript management system is completely online and includes a very quick and fair peer-review system, which is all easy to use. Visit http://www.dovepress.com testimonials.php to read real quotes from published authors. 